\title{
Studies on the Caries Susceptibility of First Molars
}

\author{
by \\ Hideaki FUKADA, Munemitsu YANAGISAWA, Yoshiko ARAKI, \\ Jun-ichi HIRATA, Osamu TAKADA, Osamu GOTO, \\ Masamichi NARIHARA and Morito AKASAKA
}

\section{Introduction}

It is generally maintained that the first molar is a key to the occlusal mechanism[1] and it plays an important role in the formation of the permanent dentition and normal bite. Also from the fact that most foods are masticated by these teeth, the first molars are indispensable from a masticatory functional point of view.

For this reason the normal development and function of these teeth deserve much attention in dental programs directed towards elementary school children[2,3,4].

However, it is recognized that a high percentage of caries incidence in first molars in the process of or immediately after eruption has already taken place. According to a report by MiYANO et al., $27.9 \%$ of the upper and $59.8 \%$ of the lower first molars suffer from caries immediately after eruption[5].

In a similar study, IWAKURA et al.[6] reported that nearly $40 \%$ of the occlusal surfaces suffer from caries in the process of eruption even if the crown is still covered by the gingiva. There have been previous research findings published concerning the reasons for this caries susceptibility immediately after eruption of the first molar. Immediately after eruption the dental substances are still immature, the pits and fissures being most susceptible to caries. The complex morphology of these teeth[7,8,9] and environmental factors such as an excessive intake of between-meal snacks containing sugar[10] are usually given as the main causes of susceptibility.

The involvement of dental plaque deposited on the occlusal surface of the crown, which is directly related to cariogenesis, was studied bacteriologically by IKEDA[11] and, by SAKAI[12] and SHIMADA[13] in the light of epidemiology.

It is held that the first molar, as compared with other teeth, takes a longer time between partial and full eruption of its crown, that is, the commencement of occlusion. The first molars are exposed to an accumulation of dental plaque much longer, resulting in caries susceptibility[14,17].

Our present knowledge regarding the caries susceptibility of the first molar suggests that it will be too late to initiate preventive measures after eruption. A method to predict the eruptive processes of the first molar by some means and to initiate caries preventive measures needs to be established at an early period. For this reason, this series of studies was concerned with the commencement of first 
Table 1 The number of study subjects

\begin{tabular}{c|cc}
\hline \hline & No. of subjects & No. of teeth \\
\cline { 2 - 3 } & 91 & 2,548 \\
$\hat{\delta}$ & 73 & 2,044 \\
\hline Total & 164 & 4,592
\end{tabular}

Table 2 The average ages at examinations

\begin{tabular}{c|ccccccc}
\hline & 1 & 2 & 3 & 4 & 5 & 6 & 7 \\
\hline \multirow{2}{*}{ Ages } & 69.5 & 72.5 & 75.5 & 78.5 & 81.5 & 84.5 & 87.5 \\
& & & & & & & Unit: in months
\end{tabular}

molar occlusion, the occlusal relationship between antagonists, the destructive conditions of deciduous second molars and with the manner of occlusal relationships on the basis of serial observations and plaster models.

\section{Materials and Methods}

For study materials a selective use was made of 240 kindergarten pupils residing in Yamagata City, Yamagata Prefecture. A total of 164 pupils, 91 boys and 73 girls, were subjected to serial observations for 7 periods at intervals of every 3 months starting in July 1978. The total number of erupted and unerupted first molars was 4,592 (Table 1).

Table 2 shows that the average age at the time of examination was 69.5 postnatal months or 5.7 years.

For examination purposes oral inspection cards were obtained macroscopically, full mouth alginate models were prepared and photographs were taken of the first molars alone using a special camera.

The oral inspection card was especially designed for this series of studies and columns were inserted that made it easy to calculate the ages and the periods of eruption of the antagonists for each study subject. The card also contained sketches of the 4 first molars so that the degree of gingival atrophy at each examination could be entered.

The gingiva which was stained by a routine method was photographed for objective assessment and a special purpose camera was manufactured at our request by the optical division of Fuji Photographic Co. By installing a periscope type tube on the lens, it could be inserted into the oral cavity without an assistant, mouth clasp or mirror (Fig. 1).

In a serial study of this kind, it is desirable that examinations should be performed at short intervals and, therefore, the four examinations a year at 3-month intervals used in the present study were considered highly effective.

The previously published serial studies dealing with eruptive aspects of the first molar are based on elementary school children[15,16,18]. The present study used kindergarten children and was made possible with the cooperation of Suzukawa Kindergarten in Yamagata City.

Like the previous reports[15,16,18], the first molars had already erupted in nearly $20 \%$ of the older kindergarten children. In this study a threefold classifica- 

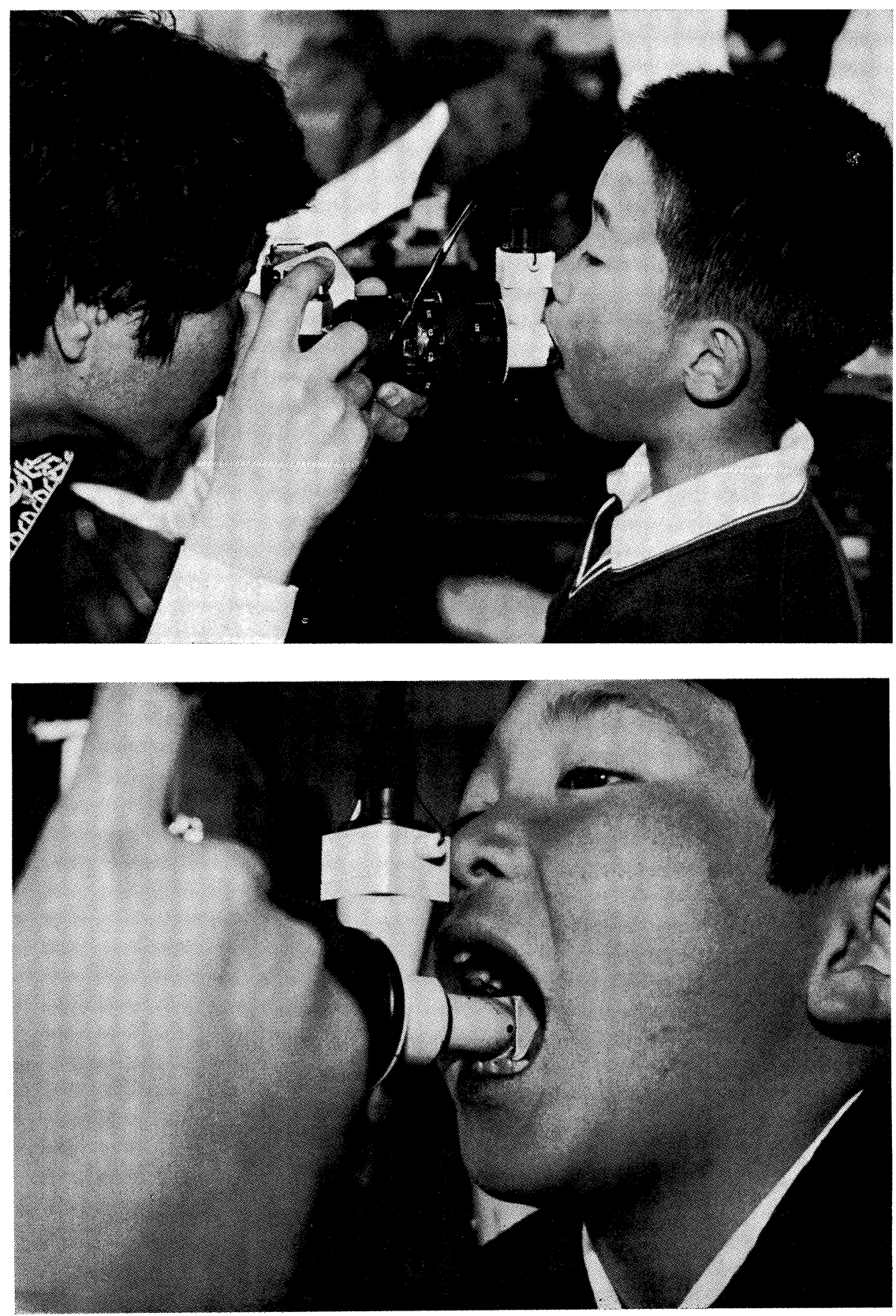

Fig. 1 A subject at photography 
Type 0

Type 1

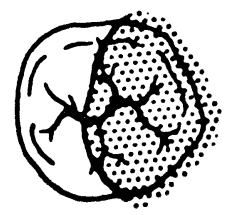

Type 2

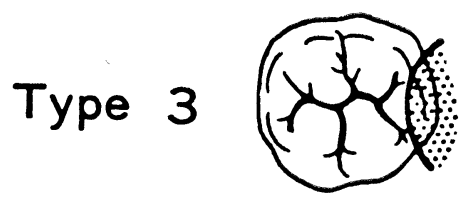

A type in which only the cusp erupted.

A type in which the mesial groove erupted.

A type in which both the mesial and central groove erupted.
A type in which the mesial, central and distal groove erupted but occlusal surface is partially covered.
A: Not in occlusion
B: In occlusion

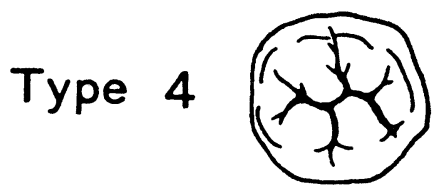

A type in which the entire occlusal surface is exposed.
A: Not in occlusion
B: In occlusion

Fig. 2 Criteria for eruptive classification

tion was adopted starting from Type 0 in which the crown was partially exposed except for fissures. Type 1 was based on the pits on the mesial, Type 2 the central and Type 3 the distal sides of the first molars in the process of eruption.

Further, cases in which the gingiva had receded from the distal portion of the crown were designated Type 4 . This was subdivided into Type $4 \mathrm{~A}$ in which the teeth were not in an occlusal relationship with their antagonists and Type 4B in which the occlusal relationship had taken place. Altogether the eruptive conditions of the first molars were classified into $6 \sim 7$ types (Fig. 2).

Based on the above sixfold division of eruptive conditions, some more measurement items were added for a better elucidation of the problem. The criteria in use 


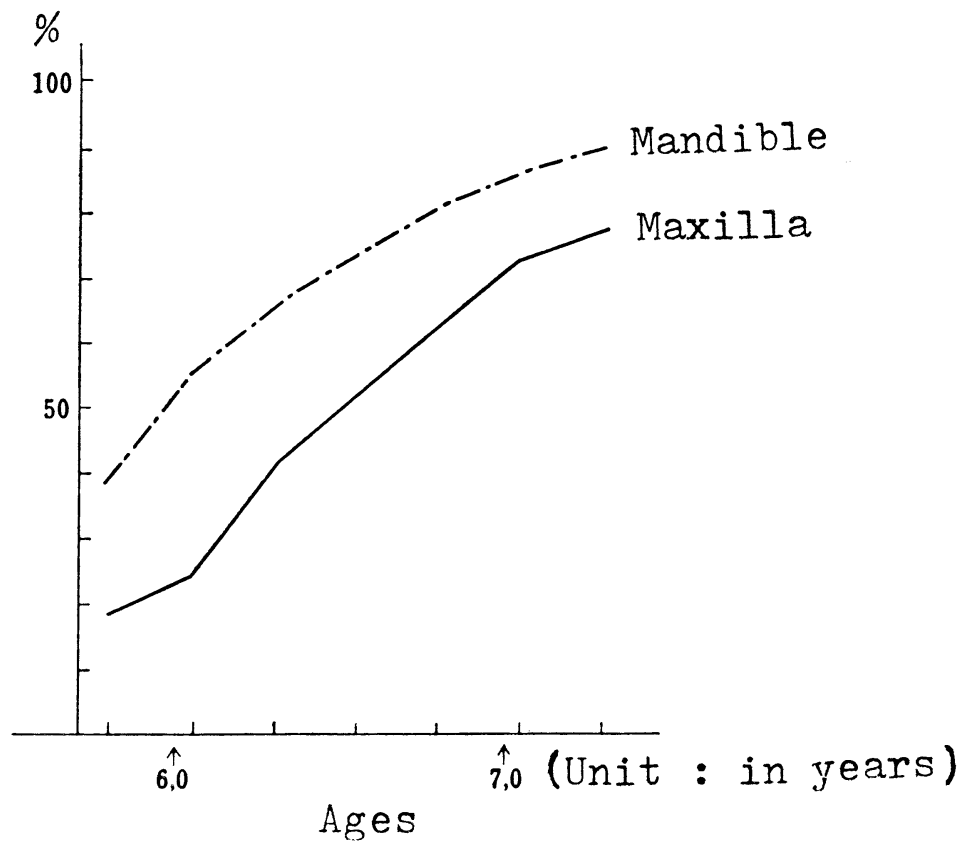

Fig. 3 The eruptive rates of the first molar between the mandible and maxilla

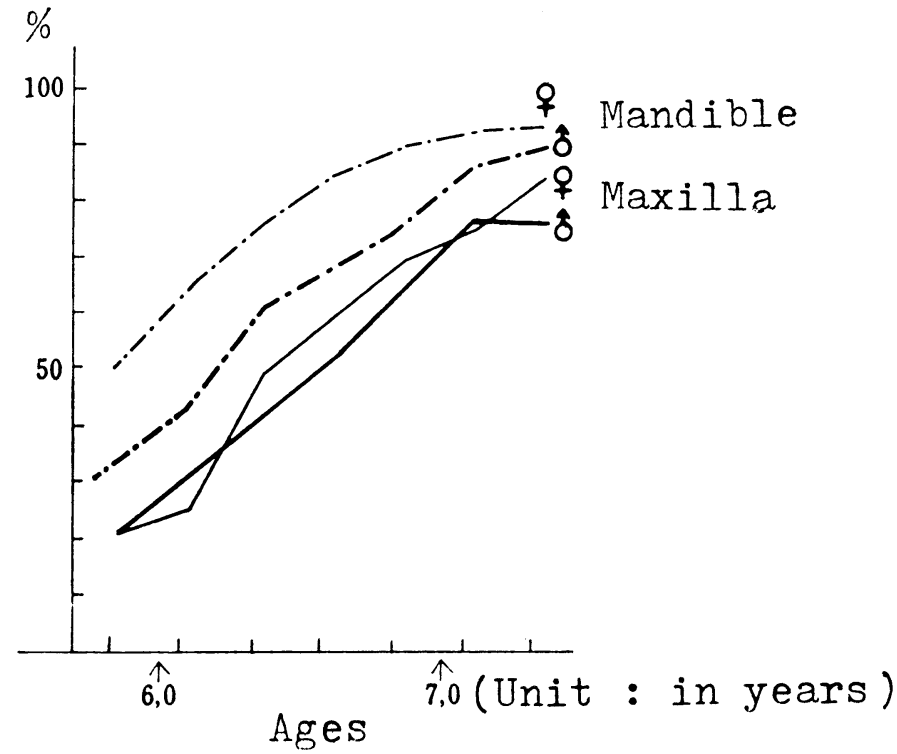

Fig. 4 The eruptive rates of the first molar between sexes 
to assess eruptive conditions of the first molar are far from satisfactory and, for this reason, fissures connected with early caries and occlusal factors were adopted in this study. The great merit of the sixfold classification was the ease with which entries could be made in the dental inspection cards with a minimum of subjective bias and the same can also be said of the full mouth models and photographic records.

\section{Findings and Discussion}

\subsection{The rate of eruption}

A fair amount of published literature is available on the rate of eruption of permanent teeth[19,20]. Most of them used elementary pupils as study subjects but in this study, use was made of kindergarten children. Fig. 3 shows that the mandibular first molars invariably gave a larger rate of eruption as compared with their maxillary counterparts in all the cases under study.

Differences in sex showed that except for a few cases the girls were found to give a larger rate of eruption than the boys (Fig. 4).

3.2 The rates of beginning occlusion and of the process of eruption

As suggested from the previous reports[14,15,16], when the teeth come into occlusal relationship with their antagonists self-cleaning activity starts and this leads to an improvement of plaque distribution on the dental surfaces, so we paid atten-

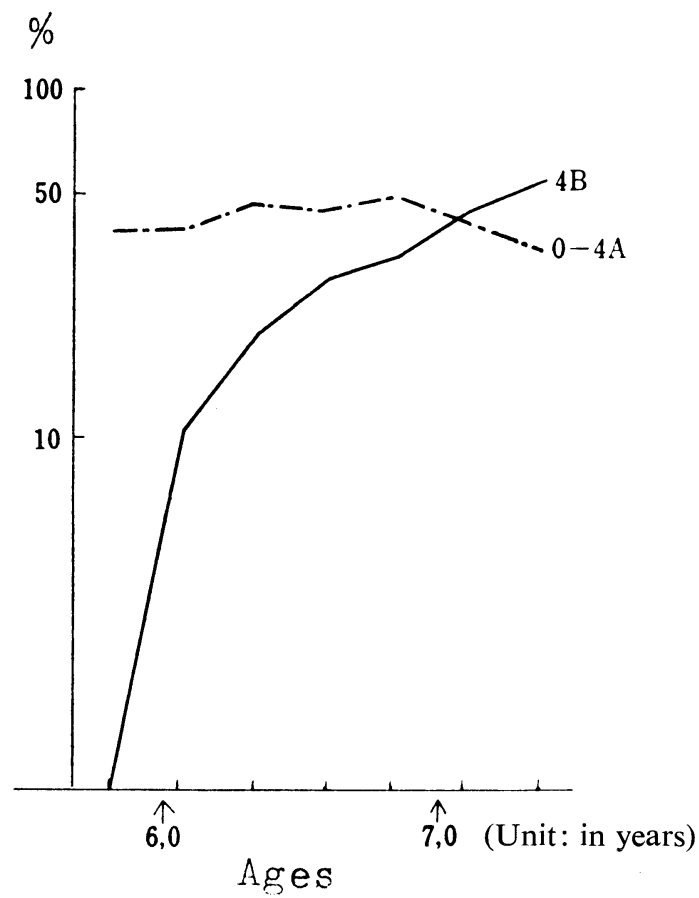

Fig. 5. A comparison of the first molar in eruptive process and initial occlusion (Mandible) 


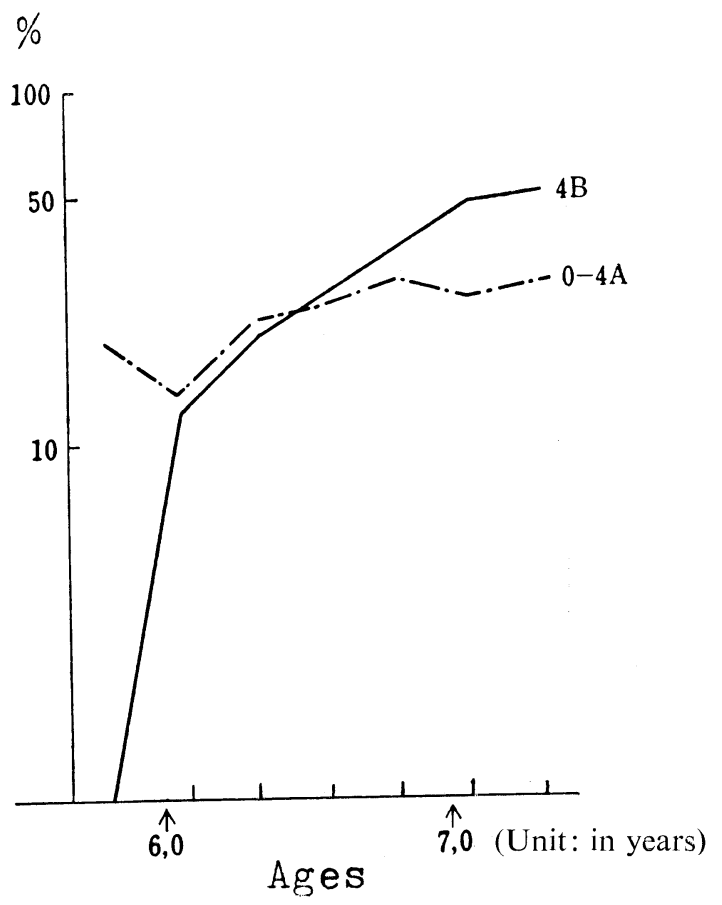

Fig. 6 A comparison of the first molar in eruptive process and initial occlusion (Maxilla)

tion to the rate of beginning occlusion. At the same time, efforts were made to examine the time period between the commencement of eruption and the beginning of occlusion. From this, it was confirmed that the children with first molars in the process of eruption were contaminated with dental plaque to a greater degree than those in whom an occlusal relationsip had already started. This finding implies that there exists a higher possibility for caries susceptibility in this period.

The rate of beginning occlusion and the process of eruption were compared (Figs. 5, 6). From this we could resonably conclude that the mandibular first molars were exposed to the possibility of caries for the longest period of time.

The published literature does not make this kind of comparison. We believe that it is a useful method in examining the eruptive conditions of the first molars from a public oral health point of view. Since self-cleaning activity of the oral cavity starts after the period when the curves of these two rates meet, more emphasis needs to be directed to preventive measures including toothbrushing in kindergarten children before this period.

3.3 The increasing rate of eruption

As shown by Fig. 7, the maximum in the increasing rate of eruption took place 3 months earlier in the girls than in the boys. Compared with the maxillary first molars, the mandibular first molars had a tendency to reach the maximum at an 


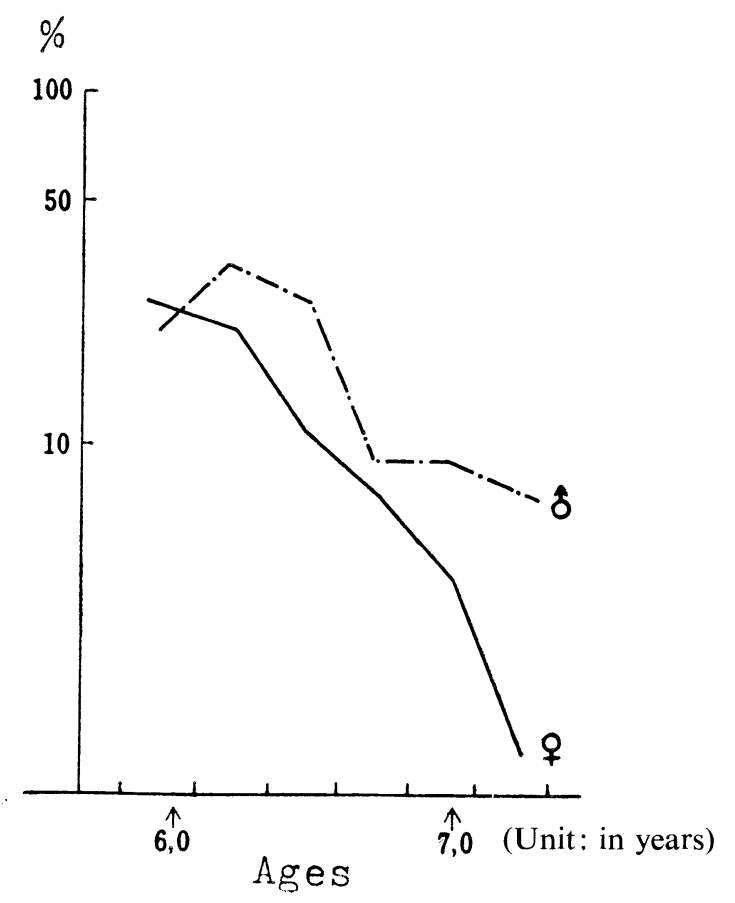

Fig. 7 The rate of increase between sexes (Mandible)

earlier period (Fig. 8). This may be related to the fact that maxillary first molars have a speedier rate of eruption (Fig. 9).

3.4 The period of eruption commencement

There are many studies dealing with eruption commencement of the first molars on the grounds that this problem is important in planning effective caries prevention.

This study made clear that the period of eruption commencement was regularly distributed among respective inspection intervals. Therefore, the commencement of eruption was assumed to be in the middle of two inspection periods. Cases in which part of the crown was exposed were also regarded as the commencement of eruption.

As given in Tables 3 and 4, the period of initial eruption was 72.3 months in the mandible and 77.1 months in the maxilla. Here again the tendency was for an earlier eruption of the mandibular first molars than their maxillary counterparts. However, cases in which the maxillary first molars erupted earlier than their mandibular counterparts or both the maxillary and mandibular first molars erupted more or less simultaneously accounted for about $21.7 \%$ of the total subjects (Table 5).

Several factors have been assigned for the differences in the periods of first molar eruption[2,22,23] and according to OTSUKA et al.[24] because of occlusal conditions arch form is an important factor which brings about changes in first molar eruption. TAKADA[25] and GoTO et al.[26] examined the possible influences of the destruction and the terminal plane of the second deciduous premolar crown that occupies a posterior position and is adjacent to the first molar in a deciduous denti- 


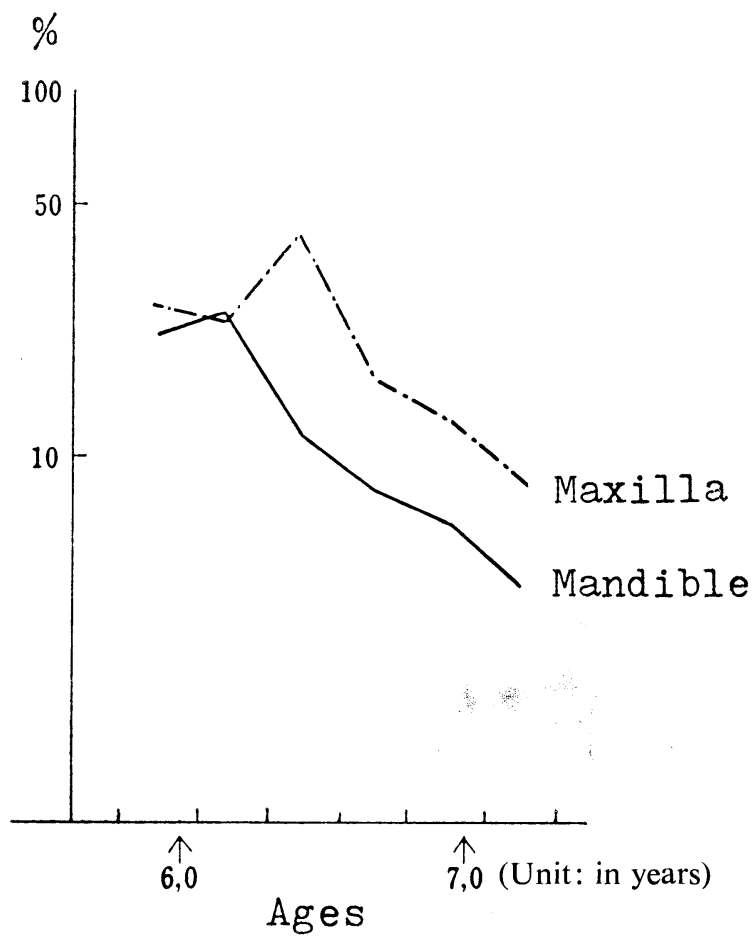

Fig. 8 The rate of increase between the maxilla and mandible

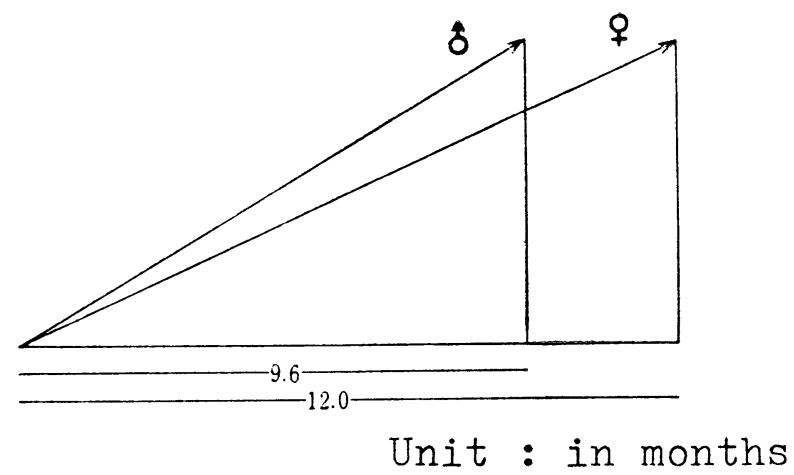

Fig. 9 Sex difference in the mandibular first molar $X$ : Time required for occlusion

Y: Distance from eruption to occlusion 


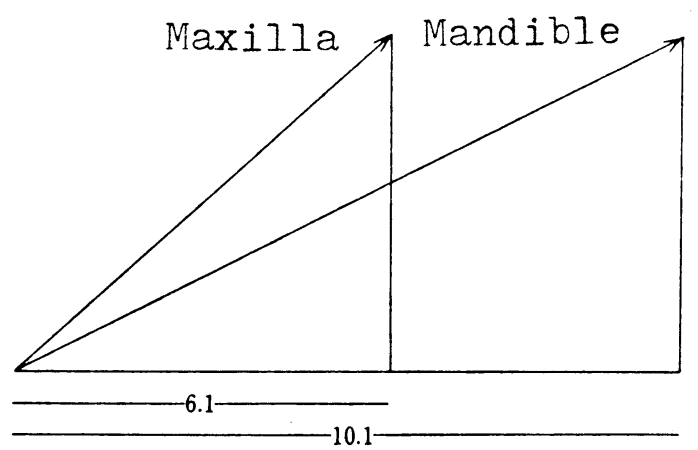

Unit : in months

Fig. 10 Time schedule of the first molar eruptions

$\mathrm{X}$ : Time before eruption

Y: Distance from eruption commencement to that of occlusion

Table 3 Initial eruption and occlusion (left)

\begin{tabular}{|c|c|c|c|c|c|c|c|c|c|}
\hline & & \multicolumn{4}{|c|}{ Eruptive period } & \multicolumn{4}{|c|}{ Occlusal period } \\
\hline & & mean & s.d. & $\max$ & $\min$. & mean & s.d. & $\max$. & $\min$. \\
\hline \multirow{2}{*}{ Total } & Maxilla & 77.3 & 5.8 & 91.5 & 64.5 & 83.0 & 6.1 & 96.5 & 69.5 \\
\hline & Mandible & 72.1 & 5.6 & 90.5 & 61.5 & & & & \\
\hline \multirow{2}{*}{$\hat{0}$} & Maxilla & 77.2 & 5.9 & 91.5 & 66.5 & 82.8 & 5.8 & 94.5 & 69.5 \\
\hline & Mandible & 74.2 & 6.2 & 90.5 & 62.5 & & & & \\
\hline \multirow[b]{2}{*}{ q } & Maxilla & 77.3 & 5.9 & 90.5 & 64.5 & 82.8 & 6.8 & 96.5 & 70.5 \\
\hline & Mandible & 70.7 & 4.8 & 80.5 & 61.5 & & & & \\
\hline
\end{tabular}

Table 4 Initial eruption and occlution (right)

\begin{tabular}{|c|c|c|c|c|c|c|c|c|c|}
\hline & & \multicolumn{4}{|c|}{ Eruptive period } & \multicolumn{4}{|c|}{ Occlusal period } \\
\hline & & mean & s.d. & $\max$. & $\min$. & mean & s.d. & $\max$. & $\min$. \\
\hline \multirow{2}{*}{ Total } & Maxilla & 77.0 & 5.8 & 91.5 & 63.5 & 83.4 & 4.8 & 95.5 & 60.5 \\
\hline & Mandible & 72.5 & 4.8 & 85.5 & 60.5 & & & & \\
\hline \multirow{2}{*}{$\hat{o}$} & Maxilla & 76.7 & 5.9 & 91.5 & 63.5 & 83.3 & 5.5 & 94.5 & 72.5 \\
\hline & Mandible & 73.3 & 4.7 & 85.5 & 62.5 & & & & \\
\hline \multirow[b]{2}{*}{ 우 } & Maxilla & 77.3 & 5.5 & 86.5 & 64.3 & 83.6 & 6.6 & 95.5 & 71.5 \\
\hline & Mandible & 71.6 & 4.8 & 80.5 & 60.5 & & & & \\
\hline
\end{tabular}

Unit: in months

Table 5 Eruptive sequence of the bi-maxillary first molars (male and female data combined)

\begin{tabular}{l|rrrr}
\hline & Right & Left & Total & \multicolumn{1}{c}{$\%$} \\
\cline { 2 - 5 } Maxilla & 15 & 16 & 31 & 12.0 \\
Simultaneous & 15 & 10 & 25 & 9.7 \\
Mandible & 102 & 100 & 202 & 78.3
\end{tabular}


tion. Accordingly, TAKADA established the following three groups relative to the destruction of the second deciduous premolar.

1) Non-crown destruction group

Cases in which either the bimaxillary deciduous premolars are not destroyed by caries or caries is limited to the occlusal surface.

2) Crown destruction group

Cases of advanced crown destruction with only the root remaining, but the second premolar in the opposite arch is intact.

3) Early loss group

Cases in which the second premolar has been extracted before the eruption of the first molar, but the second premolar in the opposite arch is intact.

As a result, TAKADA confirmed that the period of eruption was in the order of

Table 6 The absence of damage in deciduous 2 nd premolars

\begin{tabular}{|c|c|c|c|c|c|c|c|c|}
\hline & & \multirow[b]{2}{*}{ No. } & \multicolumn{2}{|c|}{ Eruptive period } & \multicolumn{2}{|c|}{ Occlusal period } & \multicolumn{2}{|c|}{ Time for occlusion } \\
\hline & & & mean & s.d. & mean & s.d. & mean & s.d. \\
\hline \multirow{3}{*}{ Maxilla } & $\hat{\delta}$ & 82 & 76.91 & 5.91 & 83.50 & 5.81 & 6.58 & 4.12 \\
\hline & 우 & 63 & 76.75 & 5.59 & 83.32 & 7.33 & 6.57 & 4.16 \\
\hline & Total & 145 & 76.84 & 5.76 & 83.42 & 6.49 & 6.57 & 4.12 \\
\hline \multirow{3}{*}{ Mandible } & $\hat{0}$ & 82 & 74.57 & 4.94 & 83.50 & $5.81^{5}$ & 8.71 & 5.11 \\
\hline & 우 & 63 & 71.76 & 5.10 & 83.32 & 7.33 & 11.66 & 4.70 \\
\hline & Total & 145 & 73.35 & 5.18 & 83.42 & 6.49 & 10.13 & 5.05 \\
\hline
\end{tabular}

Table 7 Early losses of deciduous 2nd premolars

\begin{tabular}{|c|c|c|c|c|c|c|c|c|}
\hline & & \multirow[b]{2}{*}{ No. } & \multicolumn{2}{|c|}{ Eruptive period } & \multicolumn{2}{|c|}{ Occlusal period } & \multicolumn{2}{|c|}{ Time for occlusion } \\
\hline & & & mean & s.d. & mean & s.d. & mean & s.d. \\
\hline \multirow{3}{*}{ Maxilla } & $\hat{0}$ & 2 & 72.00 & 12.02 & 79.50 & 9.89 & 7.50 & 2.12 \\
\hline & q & 0 & - & - & - & - & - & - \\
\hline & Total & 2 & 72.00 & 12.02 & 79.50 & 9.89 & 7.50 & 2.12 \\
\hline \multirow{3}{*}{ Mandible } & 占 & 8 & 69.75 & 7.04 & 85.87 & 3.33 & 14.87 & 6.99 \\
\hline & 운 & 2 & 72.00 & 0.70 & 79.50 & 7.07 & 7.00 & 7.07 \\
\hline & Total & 10 & 70.30 & 6.32 & 84.60 & 4.62 & 13.30 & 7.39 \\
\hline
\end{tabular}

Unit: in months

Table 8 Damage of deciduous 2nd premolar crowns

\begin{tabular}{|c|c|c|c|c|c|c|c|c|}
\hline & & \multirow[b]{2}{*}{ No. } & \multicolumn{2}{|c|}{ Eruptive period } & \multicolumn{2}{|c|}{ Occlusal period } & \multicolumn{2}{|c|}{ Time for occlusion } \\
\hline & & & mean & s.d. & mean & s.d. & mean & s.d. \\
\hline \multirow{3}{*}{ Maxilla } & $\hat{0}$ & 7 & 73.35 & 2.54 & 78.21 & 9.90 & 4.71 & 2.92 \\
\hline & q & 4 & 73.25 & 5.56 & 79.25 & 6.99 & 6.75 & 5.12 \\
\hline & Total & 11 & 73.22 & 3.66 & 78.77 & 4.47 & 5.45 & 3.75 \\
\hline \multirow{3}{*}{ Mandible } & $\hat{o}$ & 7 & 70.50 & 3.91 & 79.07 & 3.40 & 8.57 & 4.72 \\
\hline & 우 & 12 & 71.08 & 5.69 & 82.58 & 8.02 & 11.50 & 6.37 \\
\hline & Total & 19 & 70.86 & 5.00 & 81.28 & 6.80 & 10.42 & 5.86 \\
\hline
\end{tabular}


the early loss group, the crown destruction and the non-crown destruction groups in the mandible. Our findings are in agreement with his (Tables 6, 7, 8, Figs. 11, 12).

These results confirmed that eruption of the first molar tended to take place earlier when the second deciduous premolar was destroyed by caries or was lost entirely.

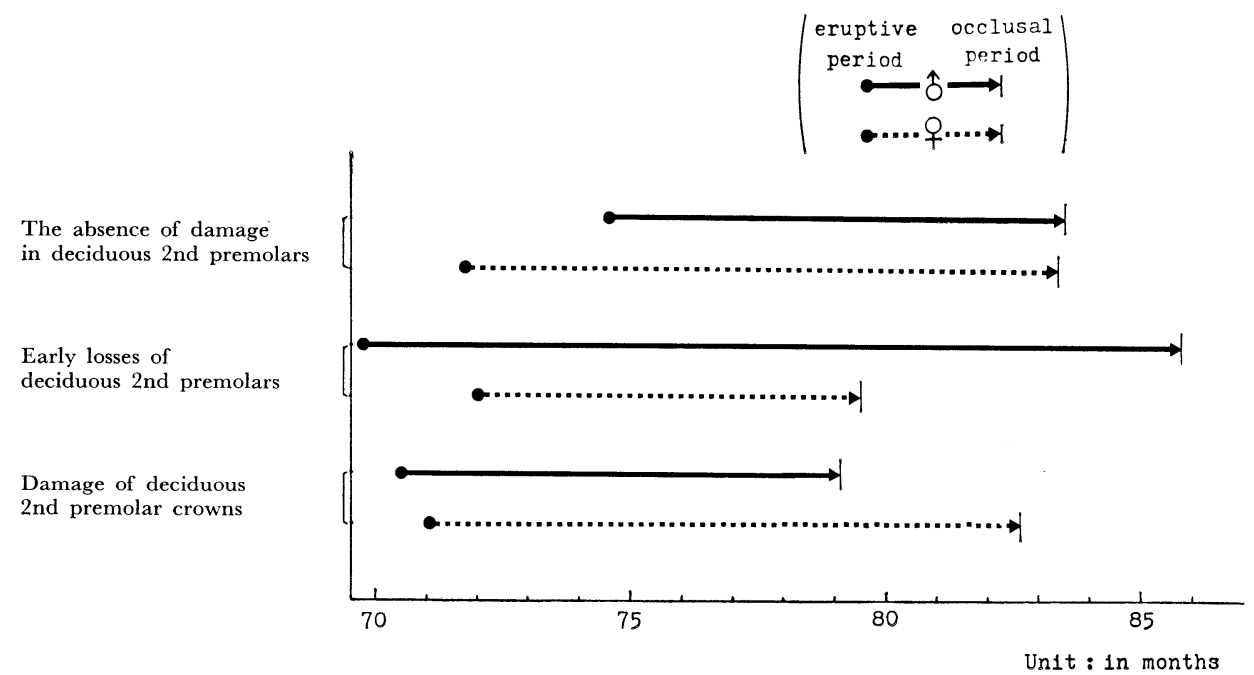

Fig. 11 A comparison of eruptive periods, commencement of occlusion and time required for occlusion (Mandible)

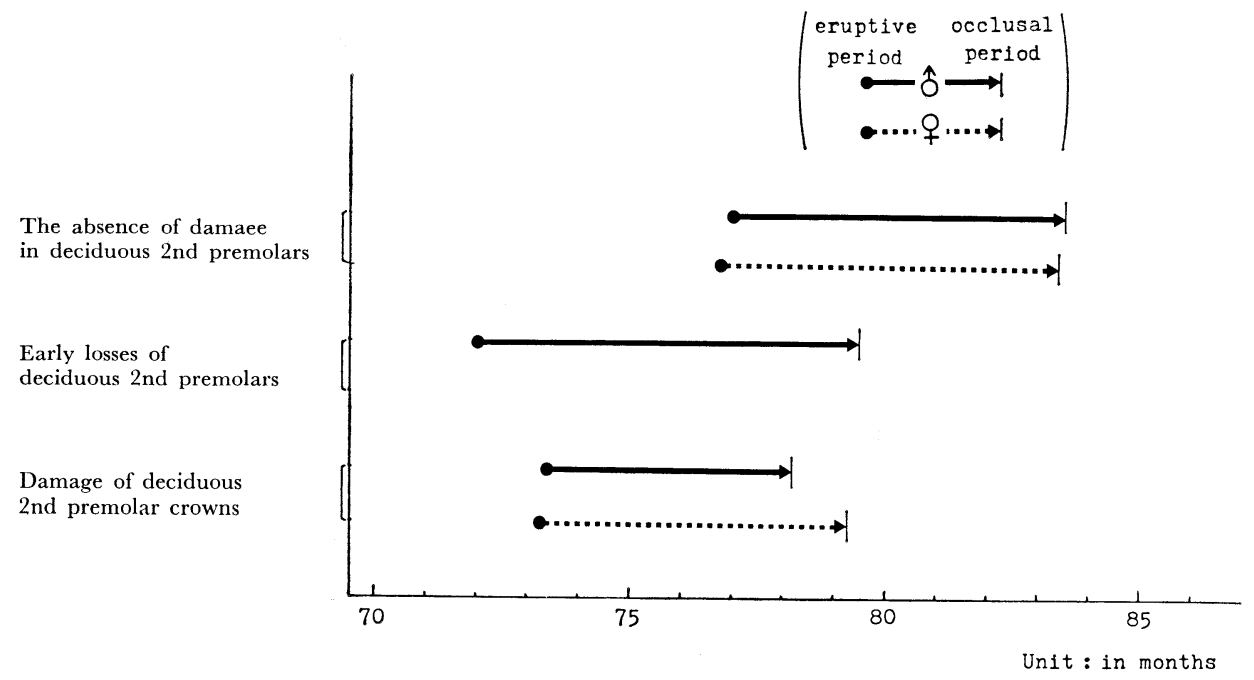

Fig. 12 A comparison of eruptive periods, commencement of occlusion and time required for occlusion (maxilla) 


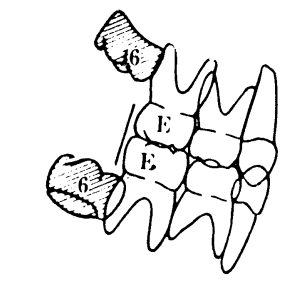

vertical type

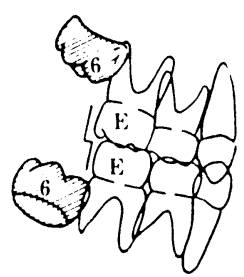

mesial step type

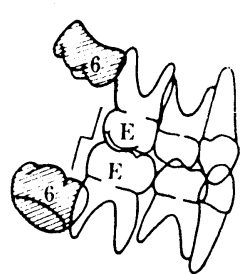

distal step type

Fig. 13 A classification of deciduous 2nd premolar occlusion

Table 9 Initial eruption and occlusal commencement of deciduous 2nd premolar

\begin{tabular}{|c|c|c|c|c|c|c|c|}
\hline & & \multicolumn{2}{|c|}{$\begin{array}{c}\text { Maxilla } \\
\text { Eruptive period }\end{array}$} & \multicolumn{2}{|c|}{$\begin{array}{c}\text { Mandible } \\
\text { Eruptive period }\end{array}$} & \multicolumn{2}{|c|}{ Occlusal period } \\
\hline & & mean & s.d. & mean & s.d. & mean & s.d. \\
\hline \multirow{3}{*}{ vertical type } & Total & 80.00 & 4.13 & 77.21 & 4.73 & 86.95 & 4.69 \\
\hline & $\hat{\delta}$ & 79.95 & 4.19 & 77.91 & 4.74 & 86.43 & 4.71 \\
\hline & 우 & 80.13 & 4.15 & 75.22 & 4.31 & 88.40 & 4.54 \\
\hline \multirow{3}{*}{ mesial step type } & Total & 83.87 & 7.06 & 79.75 & 6.12 & 91.53 & 6.75 \\
\hline & $\hat{\delta}$ & 83.60 & 7.12 & 80.30 & 5.74 & 90.80 & 6.74 \\
\hline & q & 84.64 & 7.40 & 78.21 & 7.36 & 93.64 & 6.84 \\
\hline \multirow{3}{*}{ distal step type } & Total & 81.13 & 4.47 & 81.28 & 4.89 & 88.86 & 4.08 \\
\hline & $\hat{\jmath}$ & 80.50 & 4.78 & 82.00 & 6.32 & 89.54 & 4.95 \\
\hline & 우 & 81.86 & 4.50 & 80.77 & 3.79 & 88.40 & 3.50 \\
\hline
\end{tabular}

Unit: in months

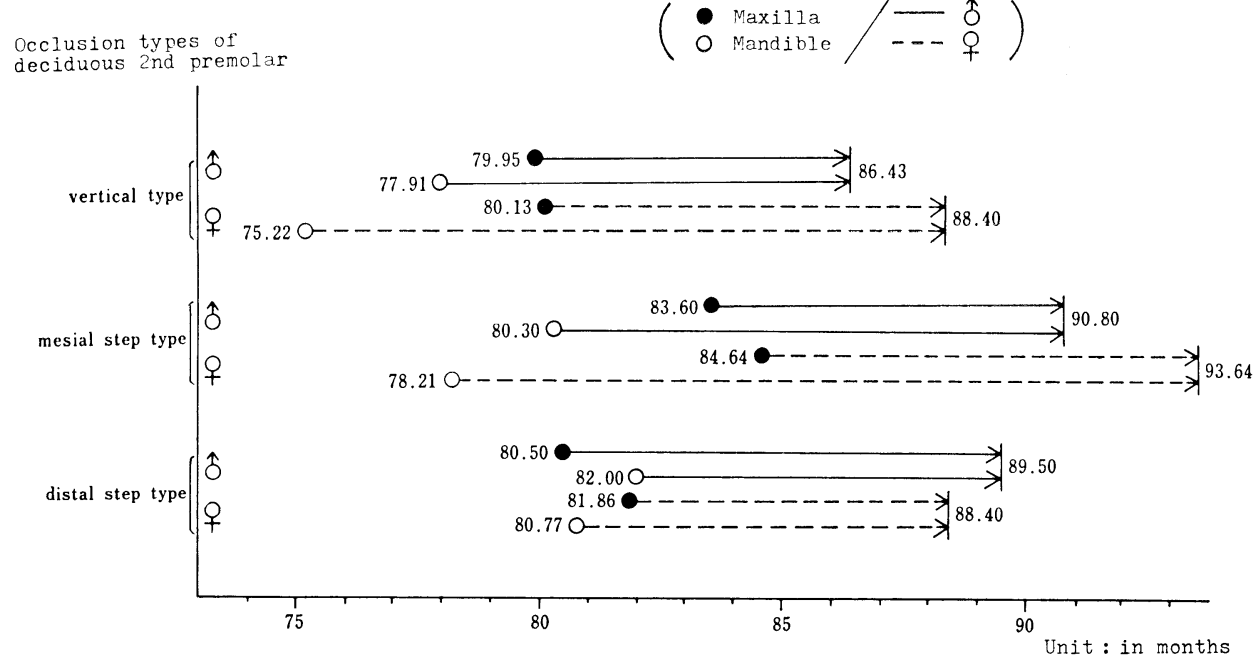

Fig. 14 A comparison of eruptive periods, commencement of occlusion and time required for occlusion 
For this reason adequate controls should be effected concerning the first molar at an early period in children in whom some kind of anomaly is found in their second premolars. Gото examined the relationship between the occlusal state of the second premolar and the eruption of the first molar. A threefold classification based on the mesiodistal relationship of the distal surface of the second premolars is as follows.

1) Vertical type

The distal surface of the bimaxillary second premolars is in a vertical relationship.

2) Mesial step type

Those cases in which the mandibular teeth are more mesial than the maxillary teeth.

3) Distal step type

Those cases in which the mandibular teeth are more distal than the maxillary teeth.

In terms of the commencement of eruption among these three types in the mandible, the vertical type was found to be the earliest followed by the mesial step and the distal step types. The order of the mesial step and the distal step types was reversed between the maxilla and mandible (Table 9, Fig. 14).

These findings indicate that by examining the occlusal relationship of the second premolars in the deciduous dentition, it is possible to predict the rapidity or delay of the first molars to a certain extent. For this reason, reasonably effective measures for caries prevention can be established by examining the deciduous dentition.

3.5 Age differences in eruption commencement

YANAGISAWA[27] considered carly cruption to be one of the factors for the high rate of caries incidence and examined such items as given in Table 10.

Although an early eruption tendency could be confirmed, no statistical differences were computed.

3.6 The commencement of occlusion

SAKAI $[14,15]$ and SHImADA et al.[16], in their examination of plaque contamination on the occlusal surface, studied the effects of the occlusion on self-cleaning activities at the time of mastication, but the exact period at which occlusion commences has not been established yet.

In this series of studies, therefore, the commencement of occlusion was investigated in terms of variations depending on different types of degrees of crown destruction and the occlusal relationship of the second deciduous premolars as well.

Since a visual inspection alone was not sufficiently accurate, plaster models were taken and when contact could be confirmed, even at one point, the subject was entered as having commenced his occlusion. The girls showed a somewhat more delayed tendency than the boys. The difference between the two was 83.2 months in the girls and 83.0 months in the boys (Tables 3,4 ).

Figs. 11 and 12 as well as Tables 6, 7 and 8 show that in the cases of the early loss group of the second molar a tendency was revealed for a delay in the commencement of occlusion on the part of the first molar.

From a caries prevention point of view, it is desirable for occlusion to start as soon as possible because of the attendant self-cleaning activity of the oral cavity. 
Table 10 Age differences of eruption

\begin{tabular}{|c|c|c|c|c|c|c|c|c|}
\hline & \multicolumn{2}{|c|}{$\begin{array}{c}\text { Okamoto } \\
\text { (1934) }\end{array}$} & \multicolumn{2}{|c|}{$\begin{array}{l}\text { Takakuwa } \\
\text { (1956) }\end{array}$} & \multicolumn{2}{|c|}{$\begin{array}{c}\text { Moyers } \\
(1963)\end{array}$} & \multicolumn{2}{|c|}{$\begin{array}{c}\text { Yanagisawa } \\
(1980)\end{array}$} \\
\hline & $\hat{0}$ & б & $\hat{\delta}$ & 우 & $\hat{0}$ & 우 & $\hat{0}$ & 오 \\
\hline Maxilla & 6.78 & 6.63 & 6.00 & 6.00 & 6.40 & 6.22 & 6.46 & 6.45 \\
\hline Mandible & 6.38 & 6.02 & 6.00 & 5.60 & 6.21 & 5.49 & $\begin{array}{l}6.25 \\
\text { Unit }\end{array}$ & $\begin{array}{l}6.05 \\
\text { years }\end{array}$ \\
\hline
\end{tabular}

Table 11 Time required for the commencement of occlusion

\begin{tabular}{cl|rc}
\hline & & mean & s.d. \\
\hline \multirow{2}{*}{ Total } & Maxilla & 6.1 & 3.9 \\
& Mandible & 10.1 & 5.7 \\
& Maxilla & 6.2 & 3.9 \\
& Mandible & 9.3 & 5.5 \\
& Maxilla & 5.8 & 3.9 \\
& Mandible & 12.0 & 5.5 \\
& & & Unit: in months
\end{tabular}

However, this is reversed in the early loss group. Needless to say, in children in whom the extraction of teeth is called for, the oral conditions are already aggravated and adequate instruction is necessary to prevent the possibility of caries of the first molar.

In the establishment of the occlusal relationship of the second deciduous premolar, the vertical type takes place the earliest followed by the distal and mesial step types (Table 9, Fig. 14). Because children belonging to the mesial step type tend to be delayed in the commencement of occlusion, proper countermeasures for caries prevention in this period are deemed necessary.

3.7 The time length before occlusion commencement

It is maintained that teeth which are not yet in an occlusal relationship are exposed to the danger of plaque contamination and an easy susceptibility to caries. However, upon the establishment of an occlusal relationship the self-cleaning activity of the oral cavity begins and, therefore, the time length before occlusion commencement needs to be minimized for the purpose of caries prevention. According to YANAGISAWA[27], the mandibular first molar takes a longer time to erupt in both boys and girls (Table 11). This tendency is more pronounced in girls (Figs. 9, 10). These figures show a fairly shallow vector slope angle, indicative of the fact that the mandibular teeth are delayed in the speed of eruption and they also show that this tendency is more pronounced in girls than in boys.

It has been held that one of the reasons for the differences in the rate of caries susceptibility between the maxillary and mandibular teeth is due to difference in their eruptive schedules[28]. This study confirmed the fact that this difference is ascribed rather to the speed of eruption.

TAdADA[25] reported that more or less the same length of time is consumed in eruption of the non-crown destruction and destruction groups of the second deciduous premolar and, in the case of the early loss group, the difference is statistically greater (Tables 6, 7, 8, Figs. 11, 12). 
According to Gото[26], the order of eruption of the mandibular teeth is the mesial then the vertical and distal step types in common with both sexes. But, in the maxillary teeth there seemed to be no definite pattern when the data for the males and females were combined. A longer tendency was recognized in the boys of the distal step type (Fig. 14).

To sum up, in girls the time length before occlusion commencement of the mandibular teeth may be explained by biological sex differences. It was also confirmed that when there is an early loss of the second deciduous premolar with the mandibular teeth in the mesial step type occlusal relationship, there is a pronounced delay in the time required for eruption. The teeth under these conditions are apt to be exposed to an accumulation of plaque for a longer period of time and, to cope with this situation adequte measures for caries prevention need to be performed.

Unit : percentage

\begin{tabular}{cc|c|c|c|c|c|} 
Maxilla & 14.3 & 7.1 & 7.9 & \multicolumn{2}{c|}{50.0} & 20.6 \\
\hline Type & 0 & 1 & 2 & 3 & $4 \mathrm{~A}$ \\
\hline \multirow{2}{*}{ Mandible } & 6.3 & 9.7 & 10.1 & 47.9 & 25.7 \\
\hline
\end{tabular}

Fig. 15 Different types of the first molar eruption

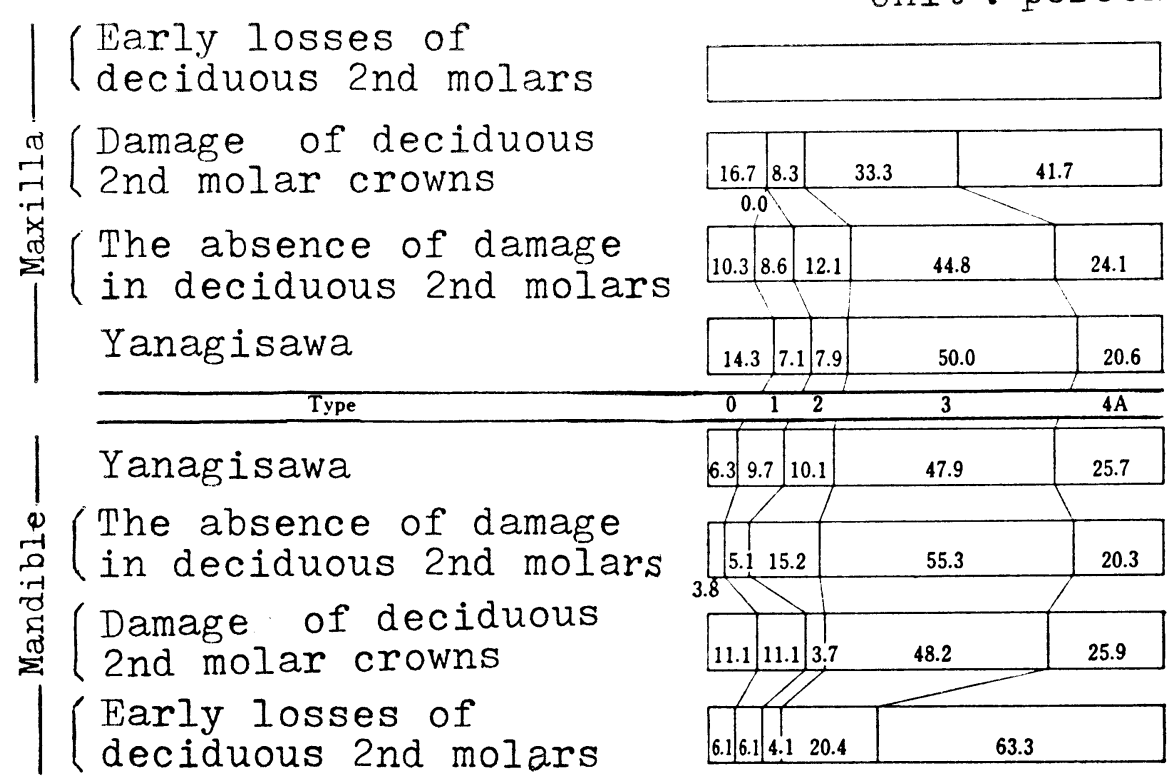

Fig. 16 The frequency of different eruptive types 


\subsection{The frequency of different eruptive types}

YosHIDA[17] pointed out that when the gingival flap remains for a long time, the possibility of a deep pocket under it becomes correspondingly large and plaque tends to attach itself when an occlusal relationship with an antagonist is absent. In

Unit : percentage

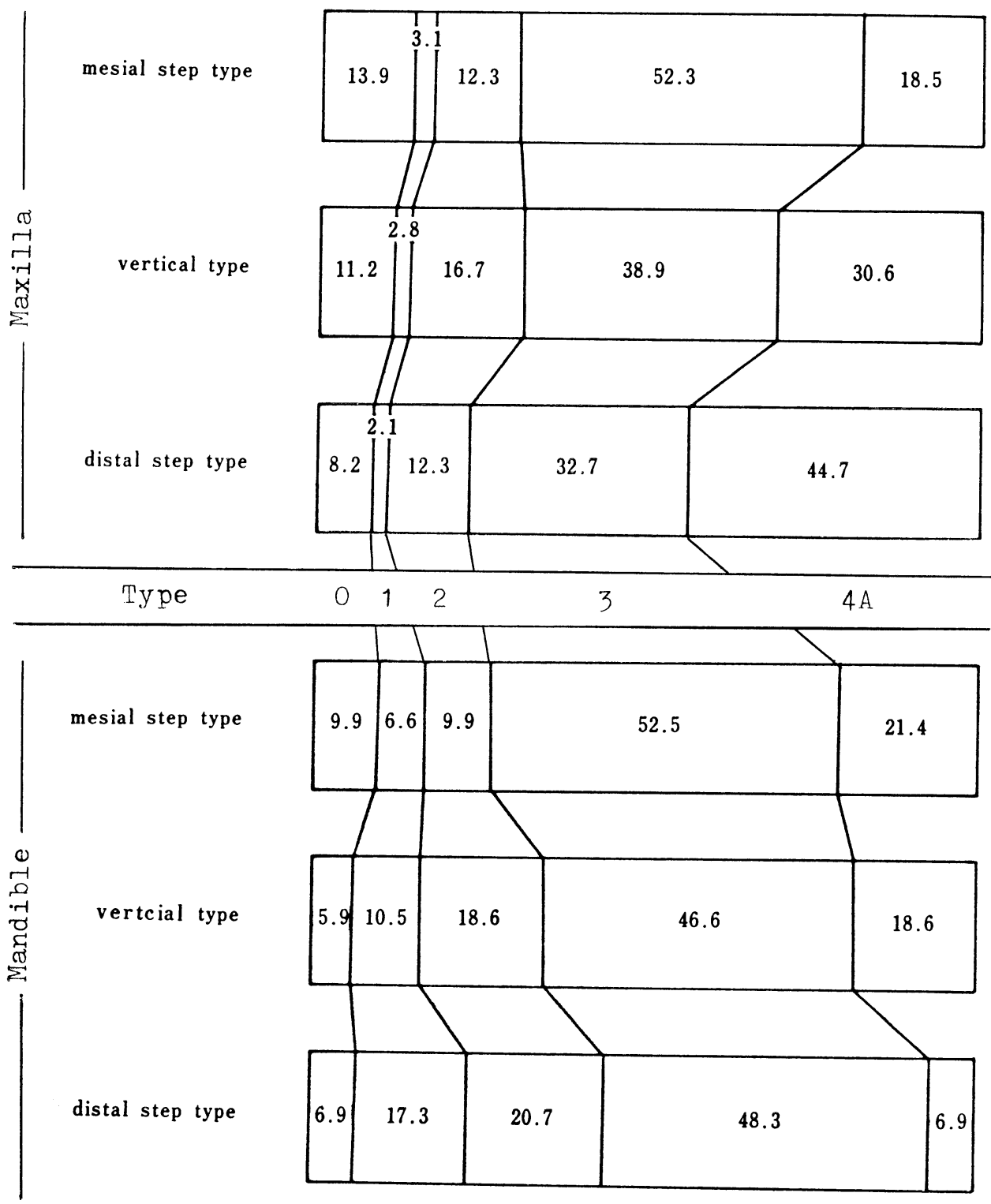

Fig. 17 Different types of the first molar eruptions 
this study, the period fell between Type 1 and Type 4. Fig. 15 gives the frequency of the respective eruptive types in percentages. The sum of Types 3 and $4 \mathrm{~A}$ was $70.6 \%$ in the maxilla and $73.6 \%$ in the mandible. The highest frequency was distributed in these types. From the fact that the first molar physiologically retains the gingival flap for a longer time it can be reasonably assumed that this tooth is caries susceptible and it follows that the rate of caries incidence is higher in the mandible as compared with the maxilla.

The high frequency of Types 3 and $4 \mathrm{~A}$ is observed in the early loss group of the second deciduous premolar as shown in Fig. 16. Moreover, the mesial step and vertical types were found to have a similar frequency in the mandible, whereas the distal step type was most frequent in the maxilla (Fig. 17).

As already stated, the mandibular first molar requires a longer time for the commencement of eruption and it was observed that the longer the gingival flap remains the higher the frequency of Type 3. This fact creates a problem in the prevention of caries. It follows then that for caries prevention the ultimate measure would be to shorten the time length required for the commencement of occlusion.

3.9 Plaque distribution on the occlusal surface in the eruptive process

ARAKI[29], one of the collaborators on this series of studies, examined the manner of plaque distribution from the commencement of eruption of the first molar through the different stages of occlusal relationship with their antagonists.

To examine the distribution of plaque a special camera was used after the plaque had been stained and slides were prepared of the occlusal surfaces. YANAGISAWA's classification scheme to determine the degree of eruption was followed (Fig. 2).

By using the occlusal plaque index (O.P.I.) of TAKAGI[30], occlusal plaque scores (O.P.S.) were established in 5 rankings from O.P.S.-0 to O.P.S.-4 for individual teeth (Table 12).

In terms of the different eruptive processes a peak point in plaque contamination in the maxilla was observed in Type 2, i.e., the high rankings of O.P.S.-3 and O.P.S.-4 accounted for nearly half of the cases between the period of eruption and the commencement of occlusion of the first molar in the mandible. Even after the commencement of occlusion, O.P.S.-2 was about $40 \%$ and, as compared with the maxilla, the plaque in pits and fissures most susceptible to caries and in their adjacent areas was not appreciably improved (Figs. 18, 19). The main reason for this is

Table 12 Rating criteria for dental plaque on the occlusal surface (OPS)

\begin{tabular}{ll}
\hline OPS-O & A case in which no stained plaque is present on the occlusal surface exposed \\
in the oral cavity. & A case in which contents of the pits and fissures are stained in the form of either \\
OPS-1 & points or lines. \\
A case in which less than $1 / 3$ of the exposed occlusal surface is covered with \\
stainable plaque. \\
A case in which $2 / 3$ of the exposed occlusal surface is covered with stainable \\
plaque. \\
A case in which more than $2 / 3$ of the exposed occlusal surface is covered \\
with stainable plaque.
\end{tabular}


Table 13 The frequency of OPS by different eruptive types and their means

\begin{tabular}{|c|c|c|c|c|c|c|c|}
\hline & & \multicolumn{3}{|c|}{ Maxilla } & \multicolumn{3}{|c|}{ Mandible } \\
\hline \multicolumn{2}{|c|}{ Eruptive type } & $\hat{\delta}$ & 우 & Total & $\hat{\delta}$ & 우 & Total \\
\hline \multirow{3}{*}{\multicolumn{2}{|c|}{$\begin{array}{l}\text { Type } 0 \\
\text { Type } 1 \\
\text { Type } 2\end{array}$}} & 0.95 & 0.56 & 0.79 & 1.00 & 1.00 & 1.00 \\
\hline & & 1.00 & 0.82 & 0.88 & 2.15 & 2.08 & 2.12 \\
\hline & & 2.60 & 1.76 & 2.22 & 2.65 & 2.79 & 2.72 \\
\hline \multirow{2}{*}{\multicolumn{2}{|c|}{$\begin{array}{cc} & \text { Type 3A } \\
\text { Type 3 } & \text { Type 3B }\end{array}$}} & 1.83 & 2.38 & 2.10 & 2.72 & 2.83 & 2.77 \\
\hline & & 1.00 & 2.30 & 1.65 & 1.92 & 0.50 & 1.71 \\
\hline \multirow{2}{*}{\multicolumn{2}{|c|}{$\begin{array}{l}\text { Type 4A } \\
\text { Type 4B }\end{array}$}} & 1.65 & 2.31 & 1.94 & 2.38 & 2.81 & 2.62 \\
\hline & & 1.32 & 1.30 & 1.32 & 1.65 & 1.78 & $\begin{array}{l}1.71 \\
\text { OPS }\end{array}$ \\
\hline
\end{tabular}

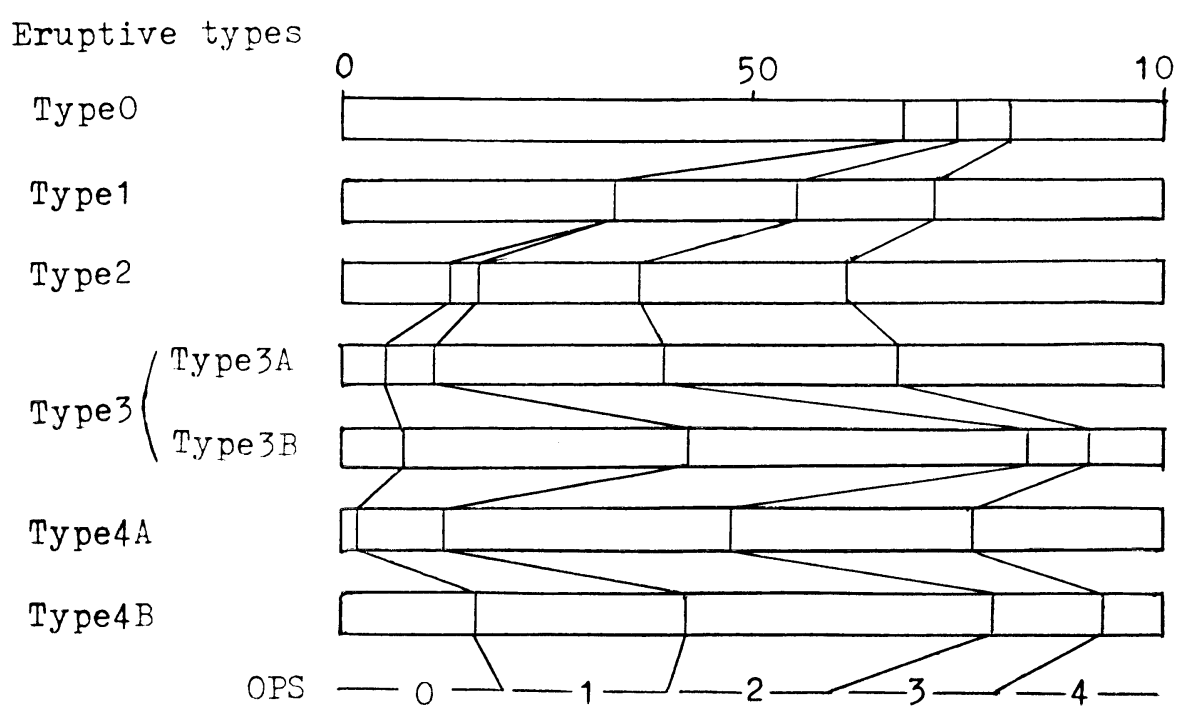

Fig. 18 The frequency of OPS incidence (mandible)

thought to be the differences in the morphology of the maxilla and mandible and the manner in which the gingiva atrophies. In agreement with a previous report by YANAGISAWA[27], it is reasonable to conclude that the mandibular first molar, which requires a longer time for the commencement of occlusion and is therefore exposed to an accumulation of plaque, has a greater potential for caries susceptibility than the maxillary first molar.

\section{Conclusions}

The following are the results of this study which was undertaken to collect basic epidemiological data for analysis of the factors involved in cariogenesis of the first molar.

1. In the commencement of eruption the mandibular teeth occurred earlier than their maxillary counterparts and this tendency was more prominent in the girls than in the boys.

2. However, the girls took a longer time before occlusion commenced. 
Eruptive types

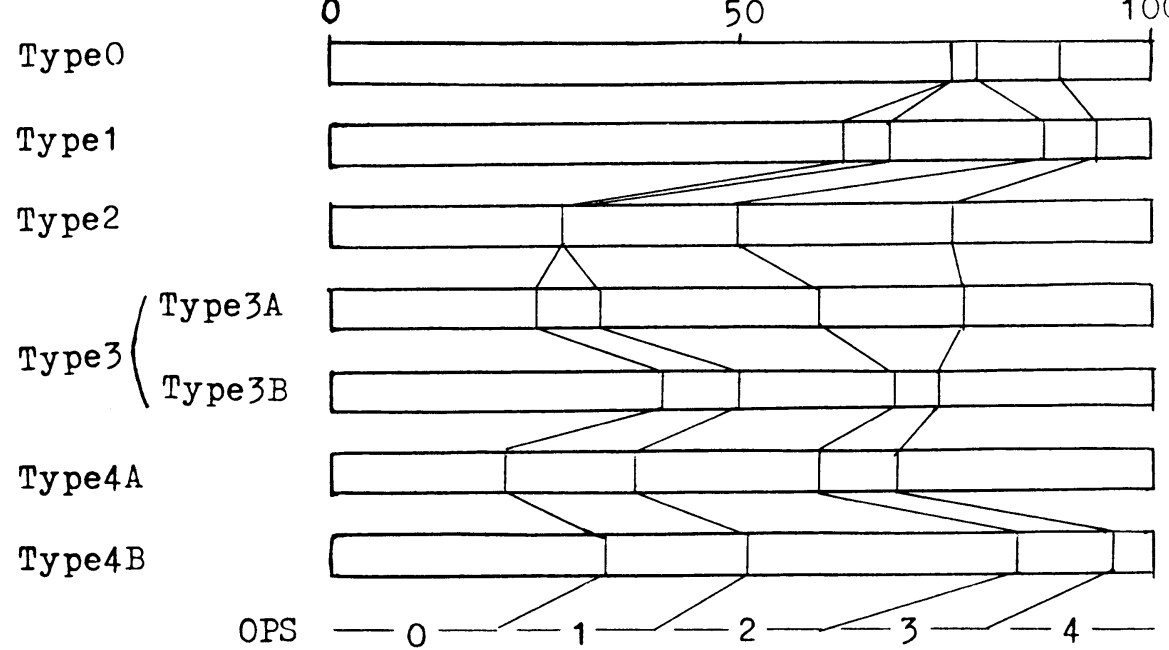

Fig. 19 The frequency of OPS incidence (maxilla)

3. Although a tendency for earlier eruption proportionately to an increase in age was observed, there were no statistical differences.

4. In both the maxilla and mandible the earliest eruption took place in the early loss group of the second deciduous premolar followed by the crown destruction and the non-crown destruction groups.

5. The early loss group, particularly in the mandible, took the longest time length before the commencement of occlusion.

6. A tendency for accelerated eruption was observed in the early loss group.

7. In the mandible a tendency for the mesial step type to erupt earliest was revealed, whereas the distal step type was found to be the earliest in the maxilla.

8. Mean occlusal surface scores in terms of different eruptive processes were greater in the mandible as compared with the maxilla.

9. Even after the establishment of occlusal contact, the plaque in the pits and fissures and their adjacent areas did not decrease. This tendency was particularly noteworthy in the mandible.

\section{References}

[1] Angle, E. H.: Treatment of malocclusion of the teeth and fractures of the maxilla, Angle's System, S. S. White Co., Philadelphia, pp. 7-27, 1907.

[2] Fukada, H., Akasaka, M. and Yanagisawa, M.: A dental examination of elementary school children, Pedodont Book, Vol. 9, pp. 298-308, 1979.

[3] Tsamtosouris, Anthi: A review of the importance of the first permanent molar, J. Pedodont., Vol. 4, 236-248, 1980.

[4] Araki, Y., Motohashi, M., Ishimi, S. et al.: A serial study of the caries of permanent teeth in elementary school children, J. Nihon Univ. dent. asso., 54: 2, 290-300, 1980.

[5] Miyano, M., Kawagoe, T. and Osawa, M.: Caries lesion of the first molar in eruptive process and immediately after eruption, J. Oral Hygiene Soc., 24: 3, 53-57, 1974. 
[6] Iwakura, M., Shimada, Y., Takagi, O. et al.: The caries of the first molar with reference to its eruptive relationship, J. Oral Hygiene Soc., 29: 2, 83, 1974 (short communication).

[7] Suga, Shoichi: The structure and composition of enamel surface considered from enamel formation, in the Symposium on dental caries (ed. Suga and Ishii), Oral Health Soc., Tokyo, pp. 5-42, 1976.

[8] Shioda, Kenji: The structure of enamel and progress of caries, in the Caries and its Prevention, Tokyo Lion Dental Pharmaceuticals Co., published by Medicodental Publishing, pp. 25-47, 1968.

[9] Ishi, Toshifumi: The onset of invasion and remineralization in deenamelization process, in the Symposium on dental caries (ed. Suga and Ishii), Oral Health Soc., Tokyo, pp. 211-232, 1976.

[10] Takeuchi, Mitsuharu: An epimiological study on the cariogenesis and sugar intake, Parts 1 and 2, Shika-Gakuho, Vol. 59, 67-74, 219-223, 324-327, 1959.

[11] IKeda, Tadashi: Streptococcus mutans and an early caries, in the Symposium on dental caries (ed. Araya), Oral Health Soc., Tokyo, pp. 27-37, 1973.

[12] Sakai, Osamu, Kobayashi, S., Enokida, C. et al.: A 6-year serial study on the plaque distribution in elementary school children, J. Oral Hygiene Soc., Vol. 28, 21-34, 1978.

[13] Shimada, Y., TaKagi, O., Inoue, H. et al.: A correlation between the plaque on occlusal surface and cariogenesis, J. Oral Hygiene Soc., Vol. 27, 45-57, 1978.

[14] Sakai, O., Kobayashi, S., Nogami, N. et al.: A 6-year serial data on the plaque distribution on permanent teeth in elementary school children, J. Oral Hygiene Soc., 28: 1, 10-20, 1978.

[15] Ditto: A 6-year data on the plaque distribution on permanent teeth in elementary school children, J. Oral Hygiene Soc., 28: 1, 21-34, 1978.

[16] Shimada, Y., TAKagi, O., INOUe, H. et al.: A correlation between the plaque on occlusal surface and cariogenesis in elementary school children, J. Oral Hygiene Soc., 27: 4, 45-57, 1978.

[17] Yoshida, T. and Ito, K.: The preventive gingival flap and preventive blocking, Dental Journal, Vol. 1, 59-66, 1979.

[18] Suzuki, Nobutake: Carious aspects of the first molar caries in elementary school children, J. Oral Hygiene Soc., 9: 4, 277-298, 1959.

[19] Miyajima, Toru: The number of existing teeth in elementary school children of Yuura and Amakusa in Kumamoto prefecture, Kyushu dent. J., Vol. 13, 143-155, 1959.

[20] Fukunari, Yone: An epideomological study on the replacement of permanent teeth and caries, Kyushu dent. J., Vol. 25, 513-578, 1972.

[21] Kamiya, Fumio: The relationship between the physique and permanent dentition, Kyushu dent. J., 8: 3, 17-29, 1954.

[22] Sato, Sadakatsu: On the relationship between physical development and permanent dentition, 144 annual meeting report of Tokyo Dental College, 1958.

[23] Shinomiya, Sumiko: A study on the permanent dentition and menarche, J. Oral Hygiene Soc., 9: 3, 257-267, 1959.

[24] Inuzuka, K., Kuwahara, M., Hattori, M. et al.: Observations of the bimaxillary first molars, proceedings of 16th Japan Pedodont. annual meeting, 42, 1978.

[25] Takada, Osaum: Studies on the caries of the first molar, Part 2, J. Nihon Univ. dent. asso., 55: 5, 805-814, 1981.

[26] Goto, Osamu: Studies on the cariogenesis of the first molar with reference to occlusal relationship, J. Nihon Univ. dent. asso., 56, 1982 (in press).

[27] Yanagisawa, Munemitsu: Studies on the Caries Susceptibility of the First Molars, Part 1, J. Nihon Univ. dent. asso., 55: 23-37, 1981.

[28] Yanagisawa, M., Miyazawa, H., Нashimoto, K. et al.: A study on the physical development of infants and the period of deciduous teeth eruption, J. Nihon Uuiv. dent. asso., 53: 2, 286294, 1979.

[29] ARAKI, Yoshiko: On the distributional state of plaque in the eruptive stage of the first molar, J. Nihon Univ. dent. asso., 56, 1982 (in press).

[30] Takagi, Okiuji: A correlationship between the dental plaque, gingivitis and caries in elementary school children, J. Oral Hygiene Soc., Vol. 21, 252-263, 1971. 